\title{
Strigolactones: past, present and future
}

\author{
Hinanit Koltai $^{1} \cdot$ Cristina Prandi $^{2}$
}

Published online: 3 May 2016

(C) Springer-Verlag Berlin Heidelberg 2016

Strigolactones (SLs) are a subject of increased scientific interest since 2008, where, they were recognized as plant hormones in two publications in Nature (Gomez-Roldan et al. 2008; Umehara et al. 2008). However, long before that time strigolactones were known to induce parasitic plant germination and later, mycorrhiza hyphal branching. Strigolactones are well placed to mediate both adaptive changes in the plant architecture and beneficial rhizosphere interactions, they have become a cutting-edge topic in plant biology and agronomy, and have great potential in modern agriculture for regulation of plant development and interactions. For these reasons, the research on strigolactones is fast growing, while our knowledge on these newly identified plant hormones is booming.

This special issue of PLANTA is dedicated to the research on strigolactones. Research and review papers present some of the recent findings and the state of the art in this subject. Stereospecificty in strigolactone biosynthesis and perception, new concepts on the role of repressor proteins in strigolactone signaling, aspects of strigolactone networks in roots and shoots, during stress conditions and plant interactions, the importance of strigolactone transport, new discoveries on strigolactone biosynthesis and on strigolactone signal perception and transduction in higher

Cristina Prandi

cristina.prandi@unito.it

Hinanit Koltai

hkoltai@agri.gov.il

1 Institute of Plant Science, Volcani Center, ARO, 50250 Bet Dagan, Israel

2 Department of Chemistry, Università degli Studi di Torino, 10125 Turin, Italy and primitive plants are some of the subjects presented in this special issue.

A European scientific network funded by a COST Action (FA1206 Strigolactones: biological roles and applications, http://www.stream.unito.it) has been established in 2013 and has been entirely dedicated to strigolactones. Most of the collaborations which have led to the results presented in the articles and reviews of this special issue were born and strengthened inside this network.

As the research on strigolactones continues to thrive we are likely to know much more on strigolactones in the next few years, positioning these plant hormones in the forefront of plant biology research.

\section{References}

Gomez-Roldan V, Fermas S, Brewer PB, Puech-Pages V, Dun EA, Pillot JP, Letisse F, Matusova R, Danoun S, Portais JC, Bouwmeester H, Becard G, Beveridge CA, Rameau C, Rochange SF (2008) Strigolactone inhibition of shoot branching. Nature 455(7210):189-194

Umehara M, Hanada A, Yoshida S, Akiyama K, Arite T, TakedaKamiya N, Magome H, Kamiya Y, Shirasu K, Yoneyama K, Kyozuka J, Yamaguchi S (2008) Inhibition of shoot branching by new terpenoid plant hormones. Nature 455(7210):195-200 